RAD Conference Proceedings, vol. 2, pp. 132-136, 2017

www.rad-proceedings.org

\title{
MERITS AND DEMERITS OF DIFFERENT METHODS FOR RADON EXHALATION MEASUREMENTS FOR BUILDING MATERIALS
}

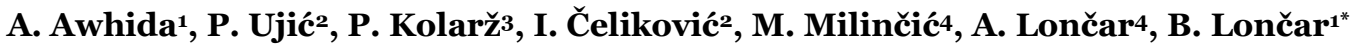

${ }^{1}$ Faculty of Technology and Metallurgy, University of Belgrade, Belgrade, Serbia

${ }^{2}$ Institute of Nuclear Sciences "Vinča", University of Belgrade, Belgrade, Serbia

Institute of Physics Belgrade, University of Belgrade, Belgrade, Serbia

4Faculty of Geography, University of Belgrade, Belgrade, Serbia

\begin{abstract}
With an increase in the awareness of the need to save energy, residents tend to live in dwellings with increasingly tight windows and doors, thus reducing the ventilation rate of indoor air which leads to an increased accumulation of radon indoors. Having in mind that a dose from an exposure to inhaled radon and its progenies can be higher than a dose received from radium in building materials, it is suggested that radon exhalation measurements should receive due attention. In this contribution, the authors compare results gathered using a few methods for radon exhalation measurement and discuss its merits and demerits.
\end{abstract}

Key words: Radon, building material, exhalation measurements

DOI: $10.21175 /$ RadProc.2017.27

\section{INTRODUCTION}

It is well known that more than $50 \%$ of the radiation dose received by the general population is due to an exposure to radon and its decay products [1]. Recent surveys and pooled analysis of epidemiological studies conducted in Europe [2], Asia [3] and North America [4] have unambiguously showed a connection between the exposure to indoor radon and lung cancer. Based on these studies, the World Health Organization (WHO) has estimated that between $3 \%$ and $14 \%$ of all lung cancers originate from exposure to radon [5].

Among several possible sources of radon in buildings, the soil underneath the building is considered to be a dominant one. On the other hand, in the upper floors of multi-storey dwellings, building materials are the major contributors to indoor radon concentration. In the era of waste reduction policies, new kinds of building material are used, such as coal ash bricks and cellular concrete blocks. These materials are built from fly ash that has a higher concentration of uranium compared to coal before combustion [6]. In addition, with an increase in the awareness of the need for saving energy, residents tend to live in buildings with more and more tight windows and doors, thus reducing the average air exchange rate. All this leads to an increase of the indoor radon concentration in multistorey buildings that is almost solely coming from the building materials [7], [8].

The technical guidance of the European Commission introduces the Activity concentration index (colloquially known as "gamma index") that takes into account that the annual effective dose received from the external exposure of inhabitants to radionuclides in building material should not be more than $1 \mathrm{mSv}$ (or $0.3 \mathrm{mSv}$, depending on dose criteria) [9]. The same guidance estimates that the radon concentration is unlikely to exceed the Commission's recommendation of $200 \mathrm{~Bq} \mathrm{~m}^{-3}$ as long as gamma doses from the building materials do not exceed $1 \mathrm{mSv}$ $\mathrm{a}^{-1}$ [9]. On the contrary, it is shown that it is possible that the concentration of ${ }^{222} \mathrm{Rn}$ exceeds $200 \mathrm{~Bq} \mathrm{~m}^{-3}$ for building material with ${ }^{226} \mathrm{Ra}$ concentrations larger than $200 \mathrm{~Bq} \mathrm{~kg}^{-1}$ [10]. The assumption of proportionality between radium content and the exhalation rate is misleading to some extent since the exhalation rate strongly depends on the emanation coefficient, porosity, permeability, diffusion length and numerous other factors. Thus, the observation of poor correlation between the radium content in building material and the radon exhalation rate is not a surprise [11]. It was indicated that for a very low air exchange rate, of the order of $0.2 \mathrm{~h}^{-1}$, the internal exposure of exhaling radon could exceed the external exposure coming from ${ }^{226} \mathrm{Ra}$ [11]. Having in mind the abovementioned, it is not surprising that the issue of radon exhalation rate is becoming more relevant and that there are numerous recent publications on this matter that use various techniques.

Methods of radon exhalation measurements are divided by the way of enclosing sample about to be measured. Two main groups are distinguished: closedchamber methods and open-chamber methods [12]. In

*bloncar@tmf.bg.ac.rs 
the closed-chamber methods a sample is enclosed in a well sealed chamber. An increase of radon concentration in the chamber is then followed [12]. On the other hand, in the open-chamber methods measurements are performed in ventilated chambers. A gas in a chamber is continuously exchanged with a radon free or low-radon gas using a pump with a known and constant gas exchange rate. Exhalation is extracted from the measured radon concentration and known gas exchange rate [12]. This contribution compares several closed-chamber radon exhalation methods developed or used in our Laboratory for Nuclear and Plasma Physics of the "Vinča" Institute of Nuclear Sciences.

\section{MATERIALS AND METHODS}

Three different methods for radon exhalation measurements were compared in this paper. Two of them are well-established closed-chamber methods, also known as "sealed-can" methods [13]: one utilizes an active device, while the other uses solid state nuclear track detectors (SSNTD) to measure radon accumulated in the chamber. The dimensions of the chamber are $26.3 \times 26.3 \times 42.4 \mathrm{~cm}^{3}$. The third method discussed in this paper is the recently developed "gamma method" [14].

The same sample used for all three measurements is of cylindrical shape with a diameter of $7.1 \mathrm{~cm}$ and a height of $12 \mathrm{~cm}$. The $45 \%$ (of weight) of sample consist of travertine from "Niška Banja" known for high radium content. The travertine was smashed in the powdered form. Travertine was mixed with a $15 \%$ of sand and $40 \%$ of cement, homogenized and shaped into proper cylindrical form. Thus obtained density of the sample was $1750 \mathrm{~kg} \mathrm{~m}^{-3}$ and ${ }^{226} \mathrm{Ra}$ concentration was $174 \pm 2 \mathrm{~Bq} \mathrm{~kg}^{-1}$. The sample was left to cure for about one month and afterwards was sealed by a beewax from all sides except for one base. Sample was then left for approximately 40 days in order to achieve equilibrium between ${ }^{222} \mathrm{Rn}$ and its progenies [14].

\subsection{The closed-chamber method with an active} device

In the closed-chamber method, the sample is enclosed in a preferably airtight chamber and the accumulation of radon exhaling from the sample is being measured. With the active device, radon growth in the chamber is being continuously measured.

In ideal cases, when the chambers are well-sealed there is no leakage of radon from them, and their volume $V\left(\mathrm{~m}^{3}\right)$ is much larger than the sample volume, radon concentration $C\left(\mathrm{~Bq} \mathrm{~m}^{-3}\right)$ in time $t(\mathrm{~s})$ can be expressed as [15]:

$$
C(t)=\frac{E A}{V \lambda}\left(1-e^{-\lambda t}\right)+C_{0} e^{-\lambda t}
$$

where $E$ is the radon exhalation rate per unit of surface area $\left(\mathrm{Bq} \mathrm{s}^{-1} \mathrm{~m}^{-2}\right), \mathrm{A}$ is the surface of the sample $\left(\mathrm{m}^{2}\right), V$ $\left(\mathrm{m}^{3}\right)$ is the total volume of the measurement system that includes volumes of the accumulation chamber, tubes and measurement chamber of the measuring device, and $\lambda$ is the radon decay constant $\left(\mathrm{s}^{-1}\right)$. Initial radon concentration in the chamber at the time when chamber is sealed is denoted as $C_{o}\left(\mathrm{~Bq} \mathrm{~m}^{-3}\right)$ and can be neglected since the chamber was sealed in a low-radon environment. From now on, radon exhalation rate per unit of surface area will be referred to as radon exhalation.

For sample pore volumes that are relatively large compared to the size of the chamber (more than 10\%), there is a high probability that radon exhalation will decrease due to a decrease of the concentration gradient between the sample pores and inside air of accumulation chamber. In our case, the container free volume is more than 50 times larger than the sample pore volume, and therefore this effect can be neglected. Nevertheless, due to the leakage of radon, it was necessary to introduce an effective decay constant $\left(\lambda_{\text {eff }}=\lambda+\lambda_{\text {leak }}\right)$ that corrects the decay constant for the removal of radon by leakage [12].

The measurement was performed using a $\mathrm{RAD}_{7}$ device from Durridge Radon Instrumentation that was connected to the chamber through a drying tube. The measurement cycle was $4 \mathrm{~h}$, while duration of the measurement was 14 days. By fitting the experimental data with formula 1 , one can obtain effective lifetime and knowing the radon decay constant, a correction to the leakage can be extracted. Detailed approach how to estimate different contributions to the effective decay constant can be found in [16].

\subsection{The closed-chamber method with SSNTD}

The only difference between this method and the one previously described is in the technique used to measure radon in the chamber. With the passive devices, such as SSNTD, it is not possible to perform continuous $\mathrm{Rn}$ measurements, but what is recorded is the track density $\rho$ on the polycarbonate detector that is directly proportional to the exposure.

Therefore, by integrating equation (1), using the effective decay constant $\lambda_{\text {eff }}$ and the relation between the radon concentration $C(t)$ and the track density $\rho$ $\left(m^{-2}\right)$ :

$$
\frac{d \rho(t)}{d t}=k C(t)
$$

where $\mathrm{k}\left(\mathrm{m}^{-2} /(\mathrm{Bq} \mathrm{s} \mathrm{m}-3)\right.$ is the calibration coefficient of the detector,

one can obtain a general expression for the radon exhalation $E$ :

$$
E=\frac{V \lambda_{e f f}}{A} \frac{1}{t-\frac{1}{\lambda_{e f f}}\left(1-e^{-\lambda_{e f f} t}\right)}\left[\frac{\rho}{k}-\frac{C_{0}}{\lambda_{e f f}}\left(1-e^{-\lambda_{e f f} t}\right)\right]
$$

The sample was put into the chamber in the area with the small concentration of radon, so ambiguity coming from the second term can be neglected.

For this method, a single measurement with a Radtrak $^{2} 囚$ detector produced by Landauer Nordic was used and dose expressed by $\rho / k$ was provided as a measurement result. In order to be able to compare the results between two closed-chamber methods, the Radtrak $^{2} \AA$ detector was exposed to the radon simultaneously with the measurement using RAD7. For the effective radon decay constant, a value extracted from the measurement with an active device was used. 


\subsection{The "Gamma method"}

This method of radon exhalation measurement has been published recently [14]. Contrary to all existing models that directly measure the concentration of exhaled radon, in the "gamma method", radon exhalation is deduced indirectly, by estimating the amount of non-exhaled radon. Non-exhaled radon is estimated by means of gamma spectrometric measurements, measuring the activity concentration of radon progenies ${ }^{214} \mathrm{Bi}$ and ${ }^{214} \mathrm{~Pb}$ that did not escape from the building material. The whole procedure and the complicated mathematical apparatus of this model are given in the reference in detail [14].

A cylindrical sample was sealed from all sides but one base and left for forty days in order to achieve an equilibrium between ${ }^{222} \mathrm{Rn}$ and its progenies. Due to this asymmetrical sealing of the sample, a gradient in radon concentration is achieved, with the lowest concentration at the open base of the cylinder and highest ${ }^{222} \mathrm{Rn}$ concentration at the sealed base of the cylindrical sample.

The sample was measured by the Ortec HPGe detector with a relative efficiency of $37 \%$, surrounded by passive lead shielding. The two-fold measurements, once with the sealed base of the sample placed on the HPGe detector and the other time with the open base of the sample placed on the HPGe detector were performed. Since the sample is open on one side, the concentration of radon progenies is the sample is not homogenous. Therefore in order to estimate the counting rate using a chosen $\gamma$-ray of radon progeny (609 keV, $1120 \mathrm{keV}$ and $17645 \mathrm{keV}$ for ${ }^{214} \mathrm{Bi}$ and 295 $\mathrm{keV}$ and $352 \mathrm{keV}$ for ${ }^{214} \mathrm{~Pb}$ ) the next step is to estimate contribution of each layer of the sample to the counting rate (i,.e. to estimate calibration coefficient of each layer) by using semi-empirical method, an EFFTRAN package [17] for example, to calculate efficiency transfer from a standard to a sample as described in details in [14]. Finally, solving the system of equations from [14], one can extract not only the exhalation rate, but the radon diffusion (and consequently radon diffusion length) and the emanation coefficient as well.

\section{RESULTS AND DISCUSSION}

Radon exhalation rate performed with a measurement with an active device was obtained by fitting experimental data on equation 1 . Exhalation rate was found to be $33.2 \pm 1.8 \mathrm{mBq} \mathrm{s}^{-1} \mathrm{~m}^{-2}$ and $\lambda_{\text {eff }}=(2.25$ $\pm 0.03) 10^{-6} \mathrm{~s}^{-1}$. Measurement with $\mathrm{RAD}_{7}$ was performed with a drying tube. Operating with the drying tube can strongly decrease humidity in the chamber and consequently dry the sample. Since the change in humidity was not considered, uncertainty coming from a change in humidity is introduced into systematic error. The radon exhalation rate of slab changes by $30 \%$ from exhalation of the sample with an ambient humidity to dried sample [16]. Due to integrated nature of measurement with $\mathrm{RAD} 7$ the systematic uncertainty estimated to be $15 \%$, (i.e. a half of the exhalation rate changes between completely dried and a sample at ambient humidity) should be taken into account.

The radon exhalation rate obtained from a measurement with a SSNTD was estimated using equation 3. The effective decay constant extracted from the measurement with RAD7 was used. Obtained value of $34.0 \pm 2.0 \mathrm{mBq} \mathrm{S}^{-1} \mathrm{~m}^{-2}$ is from the single measurement.

Beside the estimated radon exhalation rate of $32.6 \pm 1.4 \mathrm{mBq} \mathrm{s}{ }^{-1} \mathrm{~m}^{-2}$ shown in Figure 1 by using "gamma" method, the diffusion length of $0.31 \pm 0.03 \mathrm{~m}$ and the radon emanation coefficient of $0.45 \pm 0.02$ were deduced at the same time.

Results of the radon exhalation of the same sample obtained by three different methods are presented in figure 1 . The average, weighted by the variance is $33.2 \pm 0.8 \mathrm{mBq} \mathrm{s}^{-1} \mathrm{~m}^{-2}$ and is indicated by a dashed line.

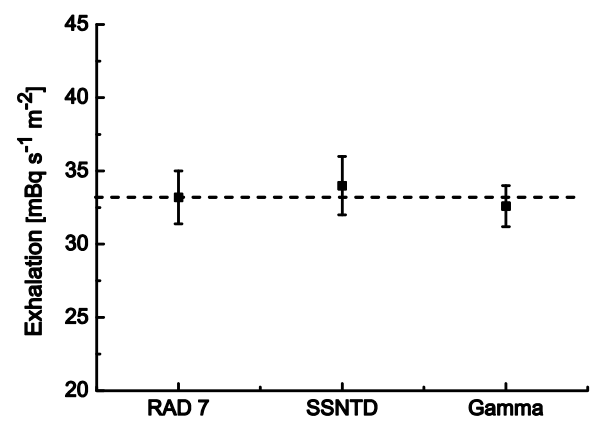

Figure 1. Results of the radon exhalation measurements from three different methods. A dashed line corresponds to the weighted average

Overall, a good agreement between the "gamma" method and the two other methods is observed. In general, the method with SSNTD is an integrating one, and thus the result cannot be corrected for any leakage of the accumulation chamber during the measurement period, while this correction can be done with an active device. For values of leakage that are small compared to the decay constant, a change of exhalation is not significant. Based on the extracted $\lambda_{\text {eff }}$ leakage is deduced to be $\lambda_{\text {leak }}=1.5 \cdot 10^{-7} \mathrm{~s}^{-1}$, and therefore if it was not used to calculate exhalation rate with a passive device, exhalation rate would be underestimated by 6 $7 \%$ of the measured one. On the other hand, leakage is not relevant for the "gamma" method.

For a method with SSNTD, the background radon concentration, present in a chamber at the moment of its sealing, is responsible for the overestimation of radon exhalation. For the method with an active device, the result can be corrected for the initial radon concentration. In order to eliminate this systematic error, the sample was put in a chamber in a very low radon environment. For the "gamma" method, background radon is not an issue.

The observed disagreement between the two methods could originate from the underestimation of measurement uncertainty.

With an active device, one can continuously measure ingrowth of the radon concentration and stop the measurements at a certain moment, when enough of statistics is provided. Using the method with SSNTD, it is not possible to obtain such feedback, so the duration of measurement should be longer to assure good statistics. This period can be shortened by using SSNTD with a larger sensitivity. With the 
"gamma" method, it is also possible to continuously measure the number of counts under the peak.

The safe handling of numerous active devices requires the usage of a drying tube installed in a closed circuit with the accumulation chamber. This way, the sample used is constantly being dried and the moisture content is changing with time, which influences the radon exhalation. In our particular measurement, this influence additional systematic error of $15 \%$. A good solution would be to use active devices that do not require the usage of a drying tube. On the contrary, in the closed chamber method with a passive device, there are no changes in the humidity. Regarding the gamma spectrometers, usually there are no changes in humidity as well, since these devices are usually working in an air-controlled environment.

As far as the time required for sample preparation is concerned, it is short for the two closed-chamber methods, while it is quite long for the "gamma" method since it is necessary to wait around 38 days to achieve an equilibrium between radon and its progenies. As far as the complexity of the analysis is concerned, the "gamma" method is the most difficult one due to rather complicated mathematical procedures and the necessity to calculate the relative counting efficiency for each infinitesimal layer of the sample [14], as opposed to the sealed-chamber method with a passive device, which requires only a single measurement.

\section{CONCLUSION}

This contribution compares three different methods for radon exhalation measurements: the closed-chamber method with an active device, the closed-chamber method with a passive device (SSNTD), and the recently developed "gamma" method. The results obtained are in the fair agreement.

The method with a SSNTD is the simplest one, but the least reliable. Due to the integrative nature of this method, it should be used in a well-controlled environment: radon leakage should be negligible, and a low $\mathrm{Rn}$ background area should be provided in the chamber.

The method with an active device is also simple to use. It is more reliable than the one with a SSNTD, since its continuous measurements enable correcting results for the radon leakage and radon background. The only drawback of this method, at least for certain devices, is the use of a drying tube disabling measurement in a moisture-controlled environment.

The "gamma" method is the most complicated one. In general, its only limitation is in a certain combination of geometry of a sample and emanation coefficient [14]. The method is not affected by the background radon concentration, the radon leakage is not an issue, and it can be performed in the moisture controlled environment. Besides, it is the only method that besides radon emanation provides values for the radon diffusion length and emanation coefficient, which would otherwise require additional equipment. These parameters are important characteristics of building materials, which are becoming an issue due to energy saving policies.
Acknowledgement: The authors acknowledge the support of the Ministry of Education, Science and Technological Development of the Republic of Serbia [P171018, P171007].

\section{REFERENCES}

1. "Sources and effects of ionizing radiation," UNSCR, New York (NY), USA, Rep. Rep. 46 (A/55/46), 2000. Retrieved from:

http://www.unscear.org/docs/publications/2000/UNS CEAR 2000 Report Vol.I.pdf

Retrieved on: Jan. 9, 2017

2. S. Darby et al., "Radon in homes and risk of lung cancer: collaborative analysis of individual data from 13 European case-control studies," BMJ, vol. 330, no. 7485, pp. 223-1 - 223-6, Jan. 2005.

DOI: $10.1136 / \mathrm{bmj} .38308 .477650 .63$

3. D. Krewski et al., "A combined analysis of North American case-control studies of residential radon and lung cancer," J. Toxicol. Environ. Health A, vol. 69, no. 7-8, pp. $533-597$, Apr. 2006.

DOI: $10.1080 / 15287390500260945$ PMid: 16608828

4. J. H. Lubin et al., "Risk of lung cancer and residential radon in China: pooled results of two studies," Int. $J$ Cancer, vol. 109, no. 1, pp. 132 - 137, Mar. 2004.

DOI: 10.1002/ijc.11683

PMid: 14735479

5. WHO Handbook on Indoor Radon: a Public Health Perspective, World Health Organization, Geneva, Switzerland, 2009.

Retrieved from:

http://apps.who.int/iris/bitstream/10665/44149/1/97 89241547673 eng.pdf

Retrieved on: Jan. 17, 2017

6. M. M. Janković, D. J. Todorović, J. D. Nikolić, “Analysis of natural radionuclides in coal, slag and ash in coalfired power plants in Serbia," J. Min. Metall. Sect. $B$ - Metall. vol. 47, no. 2, pp. 149 - 155, May 2011. DOI: 10.2298/JMMB110208008J

7. "Effects of ionizing radiation Volume II," United Nations Scientific Committee on Effects of Atomic Radiation, New York (NY), USA, Rep. A/61/46, 2006. Retrieved from:

http://www.unscear.org/docs/publications/2006/UNS CEAR 2006 Report Vol.II.pdf Retrieved on: Jan. 9, 2017

8. I. V. Yarmoshenko, A. V. Vasilyev, A. D. Onishchenko, S. M. Kiselev, M. V. Zhukovsky, "Indoor radon problem in energy efficient multi-storey buildings," Radiat. Prot. Dosim., vol. 160 no. 1-3, pp. 53 - 56, Apr. 2014. DOI: $10.1093 / \mathrm{rpd} /$ ncu110

PMid: 24723188

9. EC Directorate General Environment, Nuclear Safety and Civil Protection. (Jun. 8, 1999). Radiation protection 112 Radiological Protection Principles Concerning the Natural Radioactivity of Building Materials.

Retrieved from: https://ec.europa.eu/energy/sites/ener/files/document s/112.pdf

Retrieved on: Jan. 15, 2017

10. Naturally Occurring Radioactivity in the Nordic Countries - Recommendations, The Radiation Protection Authorities in Denmark, Finland, Iceland, Norway and Sweden, Stockholm, Sweden, 2000. Retrieved from:

https://www.sst.dk/ /media/593F6353688A4B3BB8C 8F88691248AB7.ashx

Retrieved on: Jan. 9, 2017

11. P. Ujić, I. Čeliković, A. Kandić, I. Vukanac, M. Đurašević, D. Dragosavac, Z. S. Žunić, "Internal exposure from building materials exhaling $222 \mathrm{Rn}$ and 
$220 \mathrm{Rn}$ as compared to external exposure due to their natural radioactivity content," Appl. Radiat. Isot., vol. 68 , no. 1, pp. $201-206$, Jan. 2010.

DOI: 10.1016/j.apradiso.2009.10.003

PMid: 19880324

12. N. P. Petropoulos, M. J Anagnostakis, S. E. Simopoulos, "Building materials radon exhalation rate: ERRICCA intercomparison exercise results," Science of The Total Environment, vol. 272, no. 1-3, pp. 109 - 118, May 2001.

DOI: 10.1016/So048-9697(01)00674-X

13. F. A. Abu-Jarad, "Application of nuclear track detectors for radon related measurements," Nucl. Tracks Radiat. Meas., vol. 15, no. 1-4, pp. 525-534, 1988.

DOI: $10.1016 / 1359-0189(88) 90195-1$

14. A. Awhida, P. Ujić, I. Vukanac, M. Đurašević, A. Kandić, I. Čeliković, B. Lončar, P. Kolarž, "Novel method of measurement of radon exhalation from building materials," Journal of Environmental Radioactivity, vol. 164, pp. 337 - 343, Nov. 2016.

DOI: $10.1016 /$ j.jenvrad.2016.08.009

PMid: 27552657
15. P. Ujić, I. Čeliković, A. Kandić, Z. Žunić, "Standardization and difficulties of the thoron exhalation rate measurements using an accumulation chamber," Radiat. Meas., vol. 43 no. 8, pp. 1396 - 1401, Sep. 2008

DOI: $10.1016 /$ j.radmeas.2008.03.003

16. P. Tuccimei, M. Moroni, D. Norcia, "Simultaneous determination of $222 \mathrm{Rn}$ and $220 \mathrm{Rn}$ exhalation rates from building materials used in Central Italy with accumulation chambers and a continuous solid state alpha detector: influence of particle size, humidity and precursors concentration," Appl. Radiat. Isot. vol. 64 , no. 2, pp. $254-263$, Feb. 2006

DOI: $10.1016 /$ j.apradiso.2005.07.016

PMid: 16154752

17. T. Vidmar, "EFFTRAN - a Monte Carlo efficiency transfer code for gamma-ray spectrometry," Nucl. Instrum. Methods A, vol. 550, no. 3, pp. $603-608$, Sep. 2005.

DOI: 10.1016/j.nima.2005.05.055 